Recebido: $11 / 11 / 2016$

Aprovado: 22/11/2016

\title{
O Brasil e o Prata: instabilidade e equilíbrio
}

José Viegas Filho*

Resumo: Este artigo focaliza a evolução da política do Império brasileiro no Rio da Prata ao longo do século XIX, desde as lutas dos anos de 1820 até o fim da Guerra da Tríplice Aliança; desde a busca da hegemonia até sua forma final: a construção de um modelo de cooperação internacional com base em fronteiras seguras, liberdade de navegação e repúdio a toda e qualquer hegemonia.

Palavras- chave: Bacia do Prata, Diplomacia Brasileira, Império do Brasil.

\begin{abstract}
This article focous in the political evolution of Brazilian Impire in the Plata River during the $X I X$ th, since the 1820 s batles from the and of Triple Aliance War; since the hegemony claiming from its final form: the building of an international cooperation model based in safe boundaries, navegation freedom and aversion of any kind of hegemony.
\end{abstract}

Keywords: Plata River; Brazilian diplomacy; Brazilian Impire.

\footnotetext{
* Embaixador aposentado; Ministério das Relações Exteriores.
} 
A rivalidade entre lusófonos e hispanófonos na região do Prata predominou desde o século XVI até meados do século XIX. Em 1515 navegadores espanhois exploraram o rio da Prata. Em 1531 navegadores portugueses também o fizeram. Em 1580 os espanhois fundaram Buenos Aires em caráter definitivo. Em 1628 os luso-brasileiros atacaram as reduções jesuítas espanholas em Guairá. Em 1680 os portugueses fundaram a Colônia do Sacramento, na margem oriental do Prata, e foram logo atacados pelos espanhóis. A instabilidade aí se prolonga, com reiteradas disputas militares, até meados do século XIX.

Em 1687 os espanhois fundaram, no que hoje é a parte Oeste do Rio Grande do Sul, os Sete Povos das Missões, que se transformam em outro foco de instabilidade, resolvido apenas no início do século XIX, quando forças brasileiras ocuparam a área definitivamente. Em 1724 os espanhóis fundaram Montevidéu, como fortaleza militar. Também aqui as disputas se sucederão até a formalização da independência do Uruguai em 1828.

A importância estratégica do Rio da Prata é inegável. Por ele, e exclusivamente por ele, dava-se o acesso ao coração da América do Sul, a região do grande Mato Grosso, Paraguai e Leste da Bolívia. Por aí escoava para o Atlântico boa parte da produção de minerais e metais, como o que lhe deu o nome.

Embora houvesse entre os brasileiros, desde Alexandre de Gusmão, a consciência das dificuldades que Portugal e o próprio Brasil independente teriam de enfrentar se quisessem efetivamente possuir as terras da Banda Oriental do grande rio, persistia também, na época colonial como na imperial, o vivo interesse em que não viesse a ressurgir o que um dia fora o Vice-Reinado do Rio da Prata, talvez ampliado a uma área que englobaria os atuais territórios da Argentina, do Paraguai, do Uruguai e, razão maior do temor brasileiro, o Rio Grande do Sul e, fatalmente, o Sul de Mato Grosso em uma unidade política controlada pelos hispanófonos.

A isso somou-se, em um momento, a ambição de Carlota Joaquina, infanta espanhola e rainha do Brasil, em restaurar o Vice-Reinado sob seu mando, e sob domínio espanhol. Useira e vezeira em tramar golpes que sempre fracassaram, até contra o seu próprio marido, o rei D. João VI, ela provocou a guerra entre o Brasil e o Prata.

Lembremo-nos de que existia também a ideia de um terceiro Estado na região platense, basicamente formado por Uruguai, Paraguai, Entre Rìos, Corrientes e Misiones, além, tentativamente, do Sul de Mato Grosso e do Rio Grande do Sul. Esse Estado tinha o objetivo de dividir o trecho a jusante da bacia do Prata em duas unidades independentes; A

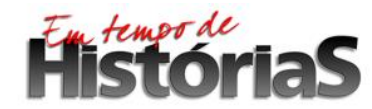


futura Argentina, no Sul, sem a margem oriental do rio Paraná e o "Uruguai Maior", com toda a margem oriental, até Corumbá e talvez mais, além de terras gaúchas. A criação desse Estado foi proposta em três ocasiões distintas: Por Artigas, na época das independências, por Rivera, na época da Farroupilha, e por López, com a Guerra do Paraguai.

Artigas tinha o "Uruguai Maior" como seu verdadeiro objetivo - tendo Montevidéu como capital - e Rivera falava abertamente dele - sem mencionar Mato Grosso -, assim como López, que não só atacou Mato Grosso, mas também Uruguaiana, na fronteira extrema com o Uruguai e a Argentina, como cabeça de ponte para separar fisicamente os dois vizinhos maiores, e, arrancando pedaços de ambos, chegar ao Prata e ao Atlântico, tendo Asunción como capital. O fato físico de que Brasil e Argentina, separando o Paraguai do Uruguai, parece ter sido sempre o principal fator de dissuasão para que esse projeto não se tornasse um objetivo permanente.

Esse Estado hipotético nada tem a ver com a Argentina, que tinha o seu próprio sonho de reconstituir o Vice-Reinado do Prata, o qual, idealmente, voltaria a englobar ao menos o Paraguai e o Uruguai, tendo Buenos Aires como capital. Afinal, como solução, consolidou-se a existência do Uruguai como país independente, evitou-se a cristalização de uma hegemonia platense, qualquer que fosse, e confirmou-se a justeza da ideia de Alexandre de Gusmão: Foise a Colônia do Sacramento e ficou o restante. Essa foi, na verdade, obra de muitas gerações das quais os brasileiros são herdeiros.

A partir dos anos de 1830, o Brasil já havia desistido de suas pretensões platenses, mas conservava o vivo desejo de preservar o Uruguai como país independente. Nossa preocupação maior, sobretudo no tempo em que Rosas governava as Províncias do Prata (1829-1852), era o perigo do ressurgimento do Vice-Reinado, cruzando o rio e chegando a fronteira brasileira. Por isso também o Brasil foi o primeiro a reconhecer a independência do Paraguai, em 1844, independência da Argentina, e não da Espanha. Mas o Paraguai se manteve arredio aos desejos brasileiros de aproximação. Sendo esta uma parte importante e sensível da história, é preciso descrever, ainda que com poucos detalhes, as suas peripécias principais.

A partir de 1810, esfacela-se o domínio espanhol na região do Prata, com a Revolução de Maio em Buenos Aires, seguida pela independência do Paraguai em 1811, independência da Espanha, mas também de Buenos Aires, e, nesse mesmo ano, a insurreição de Artigas, no atual Uruguai, que vence os espanhóis e sitia Montevidéu. Diante da ofensiva de Artigas, D. João VI, o marido de Carlota Joaquina, intervém e ocupa militarmente o território hoje 
uruguaio, obrigando Artigas a retirar-se. Contudo, seu principal aliado, a Grã Bretanha, que não apoiava os ímpetos de Dona Carlota, exerce sua pressão e D. João retira as tropas de Montevidéu. Em consequência, Artigas retorna, suas forças tomam Montevidéu e cria-se, em 1815, uma Liga Federal entre a Banda Oriental e cinco províncias argentinas.

Formava-se o conflito em torno da hegemonia no Prata entre países que ainda não haviam desenvolvido seus Estados nacionais e sua ordem interna e que mal tinham Exército ou Marinha: A Argentina, que não queria o Brasil no Rio da Prata, o Brasil, talvez globalmente mais forte, mas localmente mais fraco e o Uruguai, que até então nunca existira.

Para a Argentina, o controle das duas margens do Prata era um objetivo talvez difícil, mas não impossível. Talvez nem fosse essencial, mas era extremamente atraente, trazendo esperança de glória e riqueza na alvorada da sua independência. Impossível era não desejá-lo e difícil, naquele momento, não lutar por ele. Para o Brasil, o controle da Banda Oriental era um conceito que já vinha de muito tempo e que fora ratificado por José Bonifácio, mas cuja implementação sempre se mostrara fugidia e laboriosa. E para o futuro Uruguai, o momento significava uma primeiríssima experiência de afirmação do poder local, com interesses e fronteiras ainda por definir. ${ }^{1} \mathrm{O}$ desejo de ser livre e de poder tomar decisões e, ao mesmo tempo, a necessidade de saber negociar com os dois vizinhos maiores.

A polarização deu-se entre Brasil e Argentina. O eixo transversal, que teria como pólos o Uruguai e o Paraguai, não dera ainda reais sinais de vida, sobretudo porque o Paraguai se ensimesmara.

Em 1815 começa um período de grande fermentação política. As forças de Artigas tomam Montevidéu e formam a Liga Federal com as províncias argentinas. Em 1816 declarase a independência das Províncias Unidas do Rio da Prata. Ainda em 1816 tropas portuguesas liberadas pela derrota de Napoleão e forças gaúchas incursionam no Uruguai e em 1817 invadem Montevidéu e logram estabelecer o domínio local. Em 1819 assinam uma Convenção com o Cabildo de Montevidéu e derrotam Artigas em Taquarembó em 1820. Em 1821 D. João é o primeiro Chefe de Estado a reconhecer a independência da Argentina e nesse mesmo ano oficializa a anexação da Província Cisplatina por Tratado.

\footnotetext{
${ }^{1}$ O Uruguai teve a peculiaridade de formar-se logo ao início de sua história em torno a partidos políticos estruturados e que tinham representatividade: os Colorados, mais próximos a nós e mais fortes entre estancieiros do interior, e os Blancos, mais urbanos e mais arredios. Rapidamente o país se acostumou à ideia de que não era conveniente pertencer nem ao Império do Sul nem ao do Norte e a partir daí desenvolveu sua identidade política.
} 
Em 1823 a resistência local derrota os portugueses em Montevidéu, o novo poder anula a anexação pelo Brasil e as Províncias Unidas do Rio da Prata anexam a Banda Oriental em 1825. As relações com o Brasil já independente se rompem, a guerra é declarada contra Buenos Aires e o bloqueio de seus portos é decretado. Preocupada com o bloqueio, a Grã Bretanha, a pedido da Argentina, passa a mediar o conflito e busca pôr em movimento a ideia da independência do Uruguai como solução.

Em 1827 o conflito prossegue. As Forças terrestres do Brasil são derrotadas em Ituzaingó, enquanto que a Marinha brasileira prevalece na batalha de Monte Santiago. Nesse mesmo ano é assinada no Rio de Janeiro a Convenção preliminar de paz que faz surgir o Estado uruguaio, o que provoca indignação e tumulto em Buenos Aires. No ano seguinte, a Convenção definitiva é assinada, também no Rio de Janeiro.

O Uruguai torna-se oficialmente um país independente e sua constituição é aprovada no Rio e em Buenos Aires dois anos depois. Fructuoso Rivera, colorado, que buscava o Brasil quando em desvantagem e se afastava de nós quando no poder, torna-se o seu primeiro Presidente. (CERVO; BUENO; 2011)

Em 1829 as tropas brasileiras retiram-se definitivamente do Uruguai e no mesmo ano Juan Manoel Rosas assume o mando em Buenos Aires com poderes extraordinários. Essa evolução é percebida por políticos brasileiros como um esboço de recriação do Vice-Reinado do Rio da Prata. Em 1831, enfraquecido politicamente, D. Pedro abdica e regressa a Portugal para lutar contra seu irmão, D. Miguel, que havia conquistado o poder. Começa para nós o período das Regências e o Brasil se recolhe em incertezas e se afasta das disputas no Prata. Nas circunstâncias, a situação evolui de forma desfavorável a nós. Oribe, o General dos blancos, aliado de Rosas, toma o poder em Montevidéu e Rosas retém o governo de Buenos Aires, configurando a situação que o Império do Brasil sempre tentara evitar.

O conceito simplificado de que as disputas do Prata consistiram essencialmente em uma polarização entre o Brasil e a Argentina oculta a existência de fortes dissenções internas em cada um dos três países do Atlântico Sul. No Brasil, o período das Regências foi particularmente turbulento, com numerosos movimentos separatistas e de reivindicações sociais. No Uruguai, a relação entre blancos e colorados com frequência tomava o caráter de luta armada e na Argentina o conflito principal se dava entre o centralismo de Buenos Aires e 
o federalismo das províncias do interior. ${ }^{2}$ Essas dissenções internas tiveram papel significativo no desenvolvimento da disputa internacional. Passado o período das Regências e oficializada a maioridade de D. Pedro II ocorre uma mudança de rumo na política do Brasil e volta a predominar a ala "bonifaciana" na ação externa do Governo. Essa nova fase começa em 1843-44, mas só chega a afirmar-se como linha de ação eficaz cerca de cinco anos depois.

Em 1843 a revolução farroupilha estava viva e a existência de vínculos de apoio entre os revoltosos e o Governo uruguaio de Rivera inquietava o Império, assim como a sua ideia de uma confederação interiorana incomodava Rosas. Este enviou ao Brasil como seu representante Tomás Guido, que propôs uma aliança entre Argentina e Brasil, para derrubar Rivera. Em um relato esquemático, o lado brasileiro fez propostas adicionais, desejando incluir outros compromissos por parte da Argentina, como a liberdade de navegação no Prata, o reconhecimento dos limites brasileiros e o respeito às independências do Uruguai e do Paraguai. Mas os argentinos pleiteavam apenas aquele único objetivo e o Brasil acabou por retirar suas propostas, com o que se chegou a um acordo, no Rio de Janeiro, pelo qual Argentina e Brasil concordavam em derrubar Rivera. O Brasil ratificou o Acordo de Aliança, cujo texto foi enviado a Buenos Aires, onde Rosas recusou-se a assiná-lo, alegando que Oribe, chefe dos Blancos na guerra civil uruguaia, não fora consultado, e deixando que se formasse a impressão de que aquela era uma ideia brasileira.

Podemos imaginar a sensação que o Ministério dos Negócios Estrangeiros do Brasil nutriu ao ver-se bigodeado pelo ditador argentino, mas a época ainda não era favorável ao Brasil e não foi propícia para que uma resposta boa e imediata.

O governo estava ainda arrumando-se. De 1844 a 1849 foram onze os Chanceleres brasileiros. Nesse mesmo período o Império cometeu dois outros erros: depois de ter sido o primeiro Estado a reconhecer a independência do Paraguai em 1844, o enviado brasileiro a Assunção concluiu com o Presidente paraguaio - ad referendum do Chanceler, Paulino Soares de Souza - uma aliança bilateral contra Rosas. Paulino, em suas instruções, já havia dito ao seu representante que empregasse "todos os meios que a sua habilidade lhe sugerir para evitar

\footnotetext{
${ }^{2}$ Joaquim Nabuco cita Andrés Lamas, que diz: "A cidade de Buenos Aires, que contava perto de 80.000 almas em 1830, quando começava o governo do general Rosas, apresentava apenas, em suas extensas ruas desertas ou em estado de demolição, uma população de 40 a 43.000 almas em $1842 \ldots$ Em frente à lúgubre solidão das ruas de Buenos Aires, uma cidade nova elevava-se como por encanto às portas da antiga Montevidéu. Que protesto mais flagrante se podia esperar de um regime humano e civilizador contra o sistema de terror ... que desolava Buenos Aires? Foi em consequência dessa situação diferencial das duas capitais que, enquanto Buenos Aires via sua população diminuir de metade, a de Montevidéu se elevava a 31.189 habitantes em 1843, de 9.000 que ela contava em 1829. (Andrés Lamas, Notice sur la République Orientale de l'Uruguay, Paris, 1851, tradução do espanhol) citado por Nabuco, Joaquim, Um Estadista do Império, Ed. Nova Aguilar, 1975, nota ao pé da p. 414.
} 
que o Paraguai passe a fazer parte da Confederação Argentina e para neutralizar e diminuir a influência de Rosas". Sucede que o Chanceler, que anos depois retornaria ao Posto e daria continuidade à ação brasileira no Prata, foi logo substituído e a aliança firmada foi abandonada sem explicações dadas a Assunção, o que custou ao Império uma duradoura desconfiança.

A razão desse erro foi o intento de sondar os governos da Grã Bretanha e da França a respeito das possibilidades de uma ação conjunta no Prata. Essa ideia tampouco teve êxito, sobretudo porque nesse mesmo momento o Brasil suspendeu os privilégios civis e comerciais de que gozavam os ingleses no país, o que provocou novas exigências britânicas de concessões unilaterais e pela resolução definitiva da questão do tráfico de escravos. A sondagem foi o segundo erro, que ajudou a levar ao endurecimento da posição britânica com a adoção do Bill Aberdeen, em 1845. Três percalços em três anos recolocaram o Império do Brasil em uma linha de isolamento e reconstrução. Os europeus, por seu lado, fizeram sós a sua intervenção no Prata, mas tiveram que retirar-se quatro anos depois, cedendo a Rosas, que, dessa maneira, viu-se muito fortalecido.

O Governo brasileiro ia-se reestruturando, assim como sua política externa, o que era feito de maneira concertada, em consulta íntima entre o Ministério do Exterior, o Gabinete de Ministros, o Conselho de Estado e figuras-chave do Parlamento, além do Imperador, naturalmente, que exercia o famoso Poder Moderador. Essa convergência deu solidez a sua atuação internacional e permitiu que ela transcendesse os limites exíguos dos interesses externos da classe dos proprietários rurais e pudesse refletir melhor o lado urbano da sociedade. Forjava-se uma política externa independente, ao mesmo tempo em que o país alcançava a estabilidade e aprendia-se, finalmente, a governar o Império. Em 1849, Paulino Soares de Souza regressou à Chancelaria.

A questão platense desenvolvia-se em paralelo com a delicada e renitente questão do tráfico de escravos, que afastava o Brasil progressivamente da Grã Bretanha. Com o término do bloqueio franco-britânico a Buenos Aires, navios ingleses vieram adensar a pressão britânica contra o tráfico, provocando incidentes até mesmo em águas territoriais brasileiras. A possibilidade de que o Brasil pudesse ter que enfrentar com uruguaios, argentinos, paraguaios e britânicos ao mesmo tempo era claramente inquietante. Paulino Soares de Souza, o Visconde do Uruguai, percebeu que era crucial resolver a questão do tráfico. Uma carta sua ao Chefe da nossa Legação em Londres, em 1850, descreve com clareza a situação:

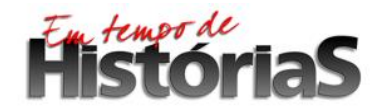


Muito mal será se a nova direção que o governo imperial tem procurado dar aos negócios relativos ao tráfico [de escravos] não nos tornar mais propício o governo britânico. Uma das razões principais por que eu procurei dar aquela direção é porque eu via que as complicações acumuladas pelo espaço de sete anos quanto às nossas relações com os generais Rosas e Oribe estavam a fazer explosão, e o pobre Brasil, tendo em si tantos elementos de dissolução, talvez não pudesse resistir a uma guerra no Rio da Prata e à irritação e abalo que produzem as hostilidades dos cruzeiros ingleses. Nec Hercules contra duo. Não podemos arder em dois fogos. (SOUZA; 1950)

O que interessava essencialmente à Grã Bretanha, e também à França, era a liberdade de navegação Prata adentro. Além da luta contra o tráfico de escravos, esse era, praticamente, seu único objetivo, diretamente correlacionado, é claro, com o de vender manufaturas aos países em que se dividiu o Vice-Reinado do Prata e ao Oeste brasileiro. Por isso se opunham a Rosas, como se haviam oposto a Dona Carlota, e a qualquer força capaz de exercer hegemonia e controlar a navegação pelo rio, o que coincidia plenamente com o interesse do Brasil.

O Chanceler brasileiro empenhou-se vivamente, junto ao Legislativo e ao Conselho de Estado, pela aprovação da lei Euzébio de Queiroz, que efetivamente proibia o tráfico, e por sua real implementação. Ele tinha perfeita consciência de que esse era o fator-chave para que o Império pudesse reverter a vulnerabilidade no Prata, vencer Rosas e eliminar definitivamente a ideia do ressurgimento do Vice-Reinado do Prata. Nesse sentido, O Brasil preparava-se para a guerra, militar e diplomaticamente. Com a aprovação da lei, a relativa normalização das relações com o Reino Unido, em 1850, evitou que os britânicos viessem a opor-se a uma ação nossa - sobretudo após o fiasco da sua própria tentativa de bloqueio a Buenos Aires, em 1849.

No relatório que apresentou à Assembleia Geral do Império em 1852, Paulino falou explicitamente sobre as intenções de Rosas: Com o controle do Uruguai e já livre da pressão anglo-francesa, ele anexaria o Paraguai e então viria sobre nós, "com força e recursos maiores do que nunca teve (para) envolver-nos em uma luta em que havíamos de derramar muito sangue e despender somas enormes". 3

No Uruguai, o Império deu, dessa vez, todo tipo de apoio para que Rivera pudesse permanecer em Montevidéu, resistindo à força de Oribe. Na Argentina, Urquiza pediu apoio

\footnotetext{
${ }^{3}$ Relatório dos Negócios Estrangeiros, 1852, pp. XIX-XX, citado em Doratioto, Francisco, O Visconde do Rio Branco: Soberania, Diplomacia e Força, PDB, p. 274.
} 
ao Brasil para lutar contra Rosas. Foi então planejada uma intervenção conjunta no Uruguai contra Oribe. Novamente escreveu Paulino: "Romperemos com Oribe ... e, auxiliados por Urquiza e o Paraguai, fácil será expelir do território oriental as tropas argentinas que sustentam Oribe", acrescentando que "Urquiza não terá remédio senão apoiar-se no Brasil e ser-lhe leal".

Em 1850 rompem-se as relações entre o Brasil e o Governo de Rosas, quem declara a guerra. O Império formalizou por Tratado a Aliança ofensiva e defensiva com Rivera, no Uruguai, e com Urquiza, em Entre Rios e Corrientes, o qual age prontamente e derrota Oribe. A equação alterara-se radicalmente: Rosas estava cercado. Nesse mesmo momento, Caxias foi nomeado Presidente do Rio Grande do Sul. Embora o apoio paraguaio não se tenha confirmado e a ação de Urquiza não tenha sido devidamente coordenada com o Brasil, em 1851, Paulino Soares de Souza fez a sua célebre frase - "apertar Rosas, e dar com ele em terra". (CERVO;2011) E Rosas foi derrotado em fevereiro de 1852, na batalha de Montecaseros, por uma tropa de quatro mil brasileiros coligada às de Urquiza, descendo pela margem ocidental do Prata, com Caxias e seus homens prontos para atacá-lo nas proximidades de Buenos Aires, a partir da margem oriental.

Tudo ocorreu de maneira formal, através da celebração de Tratados de paz e de aliança, de limites, de comércio e navegação, dando um giro completo na política de neutralidade e distanciamento com relação ao Prata, que o Brasil mantivera até 1843. Tanto o Uruguai quanto a Argentina experimentavam dificuldades financeiras e o Brasil dosava seus apoios e subsídios para que não obtivessem demasiado espaço. Paulino, com sua habitual franqueza, em outra carta a Honório Hermeto, comenta a nova situação no Prata:

(Urquiza,) "ocupado com questões intestinas, falto de recursos, não se há de poder voltar contra nós e não nos será muito difícil, livres de um poder organizado, forte e unido como o de Rosas, tirar de tais circunstâncias vantagens reais para o Império e consolidar a nossa influência no Estado Oriental." 4

Ao mesmo tempo, o próprio Paulino frisava ser indispensável "evitar o estabelecimento de novas posses e maiores complicações para o futuro. A motivação mais profunda do estabelecimento dos limites do Império deve ser a busca de segurança e

\footnotetext{
${ }^{4}$ Arquivo Histórico do Itamaraty; 272/1/3. 
estabilidade do status quo territorial mais do que qualquer perspectiva de engrandecimento do território nacional."

Apesar da linguagem por vezes franca e desabrida de Paulino, os reais objetivos buscados e conquistados pelo Brasil eram os de garantir a independência do Uruguai e do Paraguai e alcançar a estabilidade tanto nas fronteiras meridionais quanto no Prata propriamente dito, em termos que, sendo favoráveis ao Brasil, estabeleciam uma estrutura e uma doutrina duradouras de paz e progresso nessa área do Atlântico Sul.

\title{
Depois de Rosas
}

Observa-se, portanto, que os objetivos do Brasil no Prata, já amadurecidos em meados do século XIX, eram impedir que sobre a área se impusesse alguma hegemonia - e renunciar, portanto, a desejá-la para si -, preservar a livre navegabilidade dos rios de sua bacia e afiançar a estabilidade política e jurídica das fronteiras e da área como um todo. Daí decorre o propósito de preservar a todo custo a independência do Uruguai e do Paraguai e sua integridade territorial e formar com a Argentina e com eles um sistema estável.

Daí decorre também o sonho de superarmos as rivalidades e formarmos uma comunidade, colocando o interesse político-econômico conjunto acima dos sentimentos nacionalistas e procurando fortalacer-nos como bloco. Essa é a ideia que ainda hoje anima o Mercosul e que, para os brasileiros, extrapola a bacia do Prata e inclui os demais países da América do Sul, na UNASUL. No entanto, essa sempre foi uma ideia mais brasileira que da Argentina.A relação entre Brasil e Argentina formou suas raízes a partir da rivalidade entre Espanha e Portugal. Seixas Correa ressalta essa diferença de pontos de vista:

\begin{abstract}
A vinculação entre políticas de proteção contra o Brasil e o êxito do projeto nacional da Argentina é algo que se acha impregnado nos argentinos. Para a sociedade brasileira a relação com a Argentina contém-se nos limites do tempo presente, ao passo que, para a opinião pública argentina, a relação com o Brasil não deixa de refletir as vicissitudes do passado. ... Essas circunstâncias determinam, do lado argentino, um certo comportamento ansioso e do lado brasileiro, um comportamento que se caracteriza por um certo pragmatismo autoreferente que muitas vezes resvala para a insensibilidade. (SEIXAS CORREA, 2012)
\end{abstract}

O episódio de que tratamos e o período que a ele sucedeu marcam um novo tipo de convivência, não destituída das heranças do passado, mas decididamente pacífica e voltada 
para a cooperação. O Presidente Argentino que sucedeu a Urquiza, Mitre, era amigo do Brasil e companheiro da luta contra Rosas. Lutou novamente ao lado do Império na Tríplice Aliança e pôs em marcha uma política econômica modernizadora que levou o país, já no século $\mathrm{XX}$, a altos níveis de desenvolvimento. A Argentina internacionalizou-se e com isso diminuiu sua bipolaridade com o Brasil. O Brasil era um Império satisfeito e já nutria novas preocupações, que desta vez poriam a Argentina ao seu lado. Começava o segundo período da nossa relação.

Derrotados Rosas e Oribe, o Brasil conquistou uma posição de relativo conforto e ascendência. Desenvolveu uma política de aproximação com os países da área fornecendolhes empréstimos, fomentando o comércio e assegurando um convívio harmônico, ainda que por vezes escorado em breves intervenções no Uruguai, e buscou manter relacionamento equilibrado com federalistas e unitaristas na Argentina. Em 1861 Bartolomé Mitre venceu Urquiza e assumiu o governo da Argentina, consolidou o poder de Buenos Aires e manteve o bom relacionamento com o Brasil.

\section{A Tríplice Aliança}

Com o Paraguai, no entanto, persistiam desconfianças e atritos e a chegada de Francisco Solano López ao poder acentuou essas tendências. Solano López buscou a alteração da equação regional, decidido a ampliar o papel de seu país na região. Superada a introversão que caracterizara as primeiras décadas após a independência, o Paraguai tornara-se um país dotado de economia próspera e de um Estado forte e organizado.

Em meados do século XIX, o Paraguai via-se como um país "imprensado" entre seus três vizinhos. Vítima, ainda que indireta, de qualquer bloqueio que se fizesse no Prata, fosse por Buenos Aires, pelo Brasil, pela Grã Bretanha ou pela França, o país e seu Governo passaram a ansiar por uma situação de maior conforto existencial. Desprezado pelo Brasil em 1843, o que tornou, a seu ver, inconfiável em termos de apoio; diante de uma Argentina relutante em aceitá-lo como Estado independente; e tendo como principal linha de ação externa um projeto de aliança com o Uruguai, quase sempre engolfado em lutas internas que lhe reduziam sensivelmente as possibilidades de ação externa efetiva, mesmo assim, López dedicou-se a reforçar o mais possível seus efetivos militares e engajou-se na formação do já mencionado eixo transversal com o Uruguai. 
Em Montevidéu, os Blancos, então no poder, indispuseram-se simultaneamente com o Brasil, por conflitos de interesses entre estancieiros gaúchos e uruguaios, e com a Argentina, pelas simpatias mostradas por Buenos Aires para com seu rival colorado, Venâncio Flores. Nas circunstâncias, buscaram aproximar-se do Paraguai e desenvolver o eixo interiorano. López, vendo-se fortalecido, pensou ser também possível o apoio de Urquiza. A situação uruguaia, no entanto, permaneceria fluida até 1864.

Ao Brasil, que alcançara uma posição de equilíbrio a ele favorável, não interessava a guerra e sim a estabilidade da região. Ainda que o Paraguai se armasse, o Brasil demorou-se em dar a esse fato a atenção devida e custou a reaparelhar suas Forças Armadas. Do ponto de vista diplomático, no entanto, já em 1857/58, José Maria da Silva Paranhos, o futuro Visconde do Rio Branco, foi em missão ao Prata, por haver o Governo paraguaio criado obstáculos à navegação de navios brasileiros. ${ }^{5}$ (RODRIGUES, 1995; 188) Antes de chegar a Assunção, como representante do Governo brasileiro, fez escala para conversar com Urquiza, a quem fez um empréstimo e com quem celebrou um acordo de comércio e navegação. Foi também assinado um protocolo reservado pelo qual o Uruguai e a Confederação argentina reclamavam a abertura do rio Paraguai à livre navegação, justamente quando Paranhos dirigia-se a Assunção, onde, apesar de ser recebido com grandes demonstrações de poderio bélico, logrou que o Presidente Carlos Antonio López recuasse de sua posição na questão fluvial. O protocolo acima referido, aliás, previa a cooperação em caso de guerra contra o Paraguai. (DORATIOTO, 2002).

Em 1862, no entanto, persistiam as tensões. Paranhos determinou o envio de canhoneiras à área e declarou que não afastava o uso da força, mas preferia o entendimento: "A força é um meio auxiliar que não dispensa trabalhos e esforços de inteligência para a solução amigável." Disse também que a livre navegação no Paraguai constituía casus belli, mas que o Paraguai "não pode" ir à guerra contra o Império porque "isso não está nos seus interesses (e porque) não pode desconhecer a desigualdade de recursos que há entre um e outro país". (DORATIOTO, 2002). Também em 1862, a situação de rivalidade interna na Argentina evoluiu favoravelmente com a vitória de Mitre e a fundação da República Argentina, desenvolvimento positivo do ponto de vista brasileiro.

\footnotetext{
${ }^{5}$ José Honório Rodrigues observa que "o Paraguai concedia o direito de navegar seus rios a várias nações, mas recusava-os ao Brasil". O próprio Governo paraguaio dizia ao Brasil, com constância, que nada poderia negociar antes de que fosse resolvida a questão dos limites entre os países, na qual mantinha posições inaceitáveis do ponto de vista brasileiro.
} 
Em 1864, os esforços brasileiros concentravam-se no Uruguai. O Parlamento brasileiro tomou atitude hostil contra o governo Blanco, que buscava o apoio do Paraguai. O Brasil enviou um ultimatum e exigiu reparações, mas não as obteve. Tampouco obteve a concordância de Mitre para a participação armada da Argentina em uma eventual luta. Com o fim de restaurar a situação anterior, que era favorável ao Império, a Marinha brasileira bloqueou o porto de Montevidéu e enviou tropas para apoiar a rebelião de Flores, que tomou o poder. A iniciativa imperial teve pleno êxito e a mudança política no Uruguai realizou-se sem luta e sem derramamento de sangue. O Visconde do Rio Branco, enviado diplomático brasileiro, firmou com o novo governo uruguaio uma nova aliança, contrária aos planos de López. Curiosamente, apesar do êxito, Paranhos foi demitido pelo governo liberal, por não ter logrado a punição dos uruguaios que se haviam oposto ao Brasil. Pouco depois, no entanto, o Gabinete de Governo caiu no Rio de Janeiro e Paranhos declarou perante o Senado brasileiro:

Digam os nobres ex-Ministros o que quiserem ... (mas) não poderão arrancar-me esta grata convicção: que, por aquela solução, salvei a vida de dois mil de meus compatriotas, evitei as ruínas de uma capital importante e atraí as simpatias gerais do Rio da Prata para o meu país. (FRANCO, 2007; 291)

Diante dessa evolução no Uruguai, López declarou guerra ao Império e, em dezembro de 1864, invadiu Mato Grosso. Em abril de 1865, dando prosseguimento a sua ofensiva, atacou Corrientes e também o Rio Grande do Sul, o que levou à assinatura do Tratado da Tríplice Aliança. O Tratado, secreto, comprometia o Brasil, a Argentina e o Uruguai a sustentar a guerra até a queda de Solano López e proibia os aliados de fazer a paz em separado. A Aliança previa também que, terminada a guerra, a Argentina ficaria com o Chaco paraguaio até a fronteira de Mato Grosso, o que causou desgostos no Rio de Janeiro, uma vez que a independência e a integridade territorial do Paraguai sempre foram vistas pelos brasileiros como essenciais para a manutenção do equilíbrio regional. Isso foi fonte de consideráveis dificuldades, uma vez terminada a guerra e requereu grande esforço e habilidade da diplomacia brasileira para remediar a situação assim criada.

A duração da guerra, que prosseguiu mesmo depois que o Paraguai já estava militarmente derrotado, pois López continuava vivo e combatendo, causou desgastes, incertezas e inquietações entre os Aliados quanto ao trato a ser dado à nação guarani. Alterada a composição dos governos do Brasil e da Argentina, com a eleição de Sarmiento e a volta dos Conservadores ao poder no Brasil, em 1868, o Visconde do Rio Branco voltou à chefia da 
Chancelaria e empreendeu longa e delicada missão, com o objetivo de que fosse estabelecido um governo provisório em Assunção para assegurar, assim, a sobrevivência e a representatividade da nação paraguaia, o que o Governo argentino acabou por aceitar.

Paranhos permaneceu no exterior por mais de um ano, tempo que dedicou a construir uma solução política para a governança do Paraguai em termos razoáveis e aceitáveis para o Brasil e para negociar com os Aliados o Tratado definitivo de paz. Como observa Doratioto, formou-se então uma situação singular com uma aliança informal entre um vencedor, o Brasil, e o vencido, o Paraguai, contra outro vencedor, a Argentina. (DORATIOTO, 2002) O Brasil, por fim, com a guerra já terminada há dois anos, assinou um Tratado de Paz em separado com o Paraguai, o que provocou grande tensão na relação com Buenos Aires. A questão da definição das fronteiras paraguaias, no entanto, continuou sem solução até que o tema foi submetido à arbitragem do Presidente dos Estados Unidos, que decidiu pela manutenção do Chaco como território paraguaio.

\section{Conclusão}

Uma corrente da historiografia brasileira vê nas vitórias brasileiras sobre Rosas e sobre López, a expressão da hegemonia do Império brasileiro no Prata, mas não é essa a nossa percepção. A invasão do futuro Uruguai, por desígnio da família real portuguesa, em 1817, foi um erro estratégico que colocou o Brasil em oposição simultânea à Argentina, à Banda Oriental e à Grã Bretanha. Seu objetivo era a busca da hegemonia sobre o Prata e este revelou, uma vez mais, ser um objetivo de conquista sumamente problemática. A independência do Uruguai, em 1828, fez com que o Império se afastasse das questões do Prata por quinze anos e o levou a abandonar o objetivo de anexar Montevidéu e a Banda Oriental, fator sem o qual não nos parece possível que o Império do Brasil pudesse proclamar a detenção de tal hegemonia. E se acaso conseguisse conservar por um tempo significativo a posse dessa área, o que logaria seria o estabelecimento de uma relação de antagonismo permanente com a Argentina, o que, também por si só, impediria o Império de proclamar tal hegemonia.

Nesse sentido, o objetivo real do Brasil nas duas situações, contra Rosas e contra López, foi o de criar uma situação de equilíbrio entre os dois países maiores, garantindo a independência dos dois menores. Era, portanto, seu propósito o de que ninguém fosse ou 
pudesse ser hegemônico no Rio da Prata. Essa não foi uma posição meramente retórica e sim profundamente coerente com o interesse nacional do Brasil de longo prazo.

Joaquim Nabuco, em seu memorável livro "Um Estadista do Império", refere-se ao Uruguai dizendo: "Só tínhamos um interesse em relação a ele, o de termos uma fronteira sossegada e segura, para o que era essencial que ele se tornasse definitivamente independente”. E cita o Barão do Rio Branco: “A política internacional do Brasil, criada pelo partido Conservador e principalmente pelo ilustre Ministro Paulino de Souza, visconde do Uruguai, consistia então (na guerra contra Rosas), como ainda hoje (1875), em manter a independência dos dois Estados ameaçados pela ambição argentina, o Paraguai e o Uruguai”. (NABUCO, 1975, p. 413).

As ações imperiais no Prata, salvo a anexação da Cisplatina em 1817, foram sempre defensivas e preventivas e visavam a negar a possibilidade de que um mesmo país controlasse as duas margens do rio. Esse era o objetivo estrategicamente correto desde sua primeira definição por Alexandre de Gusmão - o de garantir a livre navegação dos rios da bacia do Prata, ter fronteiras claramente definidas e respeitadas e não aceitar qualquer tipo de hegemonia na região. Essa posição, desenvolvida historicamente, permitiu-nos contribuir de maneira decisiva para a criação de uma comunidade de nações sul-americanas mais caracterizada por laços de cooperação e solidariedade do que por rivalidades contraproducentes. E permitiu-nos ainda desenvolver, no século XX, a nossa identidade de país que, sendo capaz, se necessário, de usar a força, não busca, por meio dela, obter vantagens para si e sempre prefere o diálogo, a cooperação, o progresso e o respeito ao pluralismo e ao Direito Internacional.

\section{Referências Bibliográficas}

BANDEIRA, Luiz Alberto Moniz. O Expansionismo Brasileiro: o papel do Brasil na Bacia do Prata. Rio de Janeiro: Philobiblion; 1985.

BARRIO, Cesar de Oliveira Lima. A Missão Paranhos no Prata (1864-1865): diplomacia e política na Guerra do Paraguai. Brasília: FUNAG; 2010.

CERVO, Amado Luiz; BUENO, Clodoaldo. História da Política Exterior do Brasil. Brasília: Ed. UnB; 2011. CORTESÃO, Jaime. Alexandre de Gusmão e o Tratado de Madri. Rio de Janeiro: Instituo Rio Branco, 9 vols. DORATIOTO, Francisco. Maldita Guerra: nova história da Guerra do Paraguai. São Paulo: Companhia das Letras; 2002.

O Visconde do Rio Branco: Soberania. In: Diplomacia e Força, PDB.

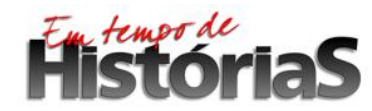


FERREIRA, Gabriela Nunes. Paulino José Soares de Souza (Visconde do Uruguai): a construção dos instrumentos da diplomacia brasileira. In: José Vicente de Sá Pimentel (Org.). Pensamento diplomático brasileiro: formuladores e agentes da política externa (1750-1964). Brasília: FUNAG, 2013, v.1, p.123-158.

FRANCO, Álvaro da Costa (Org.). Documentos da Política Externa Independente. Rio de Janeiro: Centro de História e Documentação Diplomática; Brasília: FUNAG; 2007.

FURTADO, Celso. Formação Econômica do Brasil. São Paulo: Companhia das Letras; 2012.

GOES FILHO, Synésio Sampaio. Navegantes, Bandeirantes, Diplomatas. Brasília: FUNAG, 2015.

NABUCO, Joaquim. Um Estadista do Império, Ed. Nova Aguilar, 1975.

PIMENTEL, José Vicente de Sá (Org). Pensamento Diplomático Brasileiro. Brasília: FUNAG; 2013.

RODRIGUES, José Honório; SEITENFUS, Ricardo. Uma História Diplomática do Brasil (1531-1945). Rio de Janeiro: Cilivização Brasileira;1995.

SEIXAS CORREA, Luiz Felipe de. (org). O Brasil nas Nações Unidas (1946-2011). Brasília: FUNAG; 2012.

SOUZA, José Antônio Soares de. O General Urquiza e o Brasil, em Revista do Instituto Histórico e Geográfico Brasileiro, volume, 206, janeiro/março de 1950. 